\title{
Combining 1,4-dimethoxybenzene, the major flower volatile of wild strawberry Fragaria vesca, with the aggregation pheromone of the strawberry blossom weevil Anthonomus rubi improves attraction
}

\author{
Atle Wibe ${ }^{\mathrm{a}, *}$, Anna-Karin Borg-Karlson ${ }^{\mathrm{b},}$ e, Jerry Cross ${ }^{\mathrm{c}}$, Helena Bichão ${ }^{\mathrm{d}}$, \\ Michelle Fountain ${ }^{\mathrm{c}}$, Ilme Liblikas ${ }^{\mathrm{e}}$, Lene Sigsgaard ${ }^{\mathrm{f}}$ \\ ${ }^{a}$ Bioforsk - Norwegian Institute for Agricultural and Environmental Research, Organic Food and Farming Division, Gunnars vei 6, \\ NO-6630 Tingvoll, Norway \\ ${ }^{\mathrm{b}}$ KTH - The Royal Institute of Technology, School of Chemical Science and Engineering, Department of Chemistry, SE-100 44 Stockholm, Sweden \\ ${ }^{c}$ EMR - East Malling Research, New Road, East Malling, Kent ME19 6BJ, UK \\ d NTNU - Norwegian University for Science and Technology, 7491 Trondheim, Norway \\ e Tartu University, Institute of Technology, Section of Organic Chemistry, 1 Nooruse St., 50411 Tartu, Estonia \\ ${ }^{\mathrm{f}}$ University of Copenhagen, Faculty of Sciences, Thorvaldsensvej 40, DK-1871 Frederiksberg C, Denmark
}

\section{A R T I C L E I N F O}

\section{Article history:}

Received 17 August 2012

Received in revised form

16 June 2014

Accepted 17 June 2014

Available online

\section{Keywords:}

Plant volatiles

Insect control

Synergy

(-)-Germacrene D

\begin{abstract}
A B S T R A C T
The aggregation pheromone of strawberry blossom weevil [Anthonomus rubi Herbst (Col.: Curculionidae)], a 1:4:1 blend of Grandlure I, II and racemic lavadulol, has been available for pest monitoring for several years but shows low attractancy. Attempts to control $A$. rubi using the pheromone alone were also unsuccessful. This paper reports the finding that addition of the major flower volatile from wild strawberry flowers [Fragaria vesca L. (Rosaceae)], 1,4-dimethoxybenzene (comprising 98\% of the volatiles emitted from wild strawberry flowers), to the aggregation pheromone increased trap catches by over two fold compared to the pheromone alone. There was no significant difference between the response of overwintered or summer emerged adults. Field trials in 2007-2008 in central and southern Norway, Denmark and southern England used green funnel traps with white cross vanes for the evaluations. (-)-Germacrene D, previously shown to be emitted by plants in increased amounts in the presence of pheromone producing weevils, did not improve trap catches. Thus, the combined use of the aggregation pheromone and 1,4-dimethoxybenzene is promising for improved monitoring and possibly control of this important pest of strawberry.
\end{abstract}

๑) 2014 Elsevier Ltd. All rights reserved.

\section{Introduction}

Plants produce numerous volatile compounds utilized by insects in host plant recognition and location. To develop novel crop protection strategies, it is therefore of utmost importance to understand insect-plant interactions (Agelopoulos et al., 1999). These volatiles may attract insects alone (Städler, 1992). However, the response of insects to their sex or aggregation pheromones may be

Abbreviations: PV, Plant volatile; PV1, (-)-Germacrene D; PV2, 1,4Dimethoxybenzene; Ph, Aggregation pheromone blend Grandlure I + II and lavandulol.

* Corresponding author. Tel.: +47 404800 87; fax: +47 71534405.

E-mail addresses: atle.wibe@bioforsk.no (A. Wibe), akbk@kth.se (A.-K. BorgKarlson), jerry.cross@emr.ac.uk (J. Cross), helena.bichao@ub.ntnu.no (H. Bichão), michelle.fountain@emr.ac.uk (M. Fountain), ilme.liblikas@ut.ee (I. Liblikas), les@ plen.ku.dk (L. Sigsgaard). enhanced or inhibited by host volatiles (Landolt and Phillips, 1997). The effect of enhancement of aggregation pheromones by plant volatiles has been documented for the boll weevil [Anthonomus grandis Boheman (Coleoptera: Curculionidae)] (Dickens, 1989), a species of the same genus as the strawberry blossom weevil [Anthonomus rubi Herbst, (Coleoptera: Curculionidae)] studied in the present work. In the northern part of Europe, $A$. rubi is one of the major pests on cultivated strawberry [Fragaria ananassa L. (Rosaceae)]. Early in the spring, adult weevils migrate from overwintering shelters to strawberry fields. Here they start feeding on the foliage and mate at the onset of bud formation. The eggs are deposited singly into flower buds which the weevils partially sever from their stalks. The bud formation is thus terminated and the bud will not open, and this leads to a direct loss of crop (Popov, 1996; Cross and Easterbrook, 1998).

The pheromone system of $A$. rubi was investigated by Innocenzi et al. (2001) and led to the identification of three male-specific 
compounds. Two of these compounds are also components of the aggregation pheromone of the boll weevil, A. grandis, Grandlure I and II (Tumlinson et al., 1969). Traces of Grandlure III and IV were also present but not necessary for attraction. The third malespecific compound of $A$. rubi was lavandulol. In the presence of pheromone-producing weevils on F. ananassa plants, germacrene D was collected in increased amounts (Innocenzi et al., 2001). This is a known volatile also from strawberry plants thus this increase may be due to production by the weevils or a plant response to feedinginduced damage.

Cross et al. (2006a,b) showed that sticky stake traps baited with the aggregation pheromone can successfully be used as a monitoring tool, but were not effective in controlling A. rubi. These sticky stake traps with glue for catching weevils were not practical for strawberry producers, thus never became a success for farmers in monitoring weevils. However, funnel traps with A. rubi aggregation pheromones for monitoring are sold in United Kingdom and used by several farms.

Bichão et al. (2005a) showed that the neurons on the antenna of A. rubi are narrowly tuned by responses to a few structurally related sesquiterpenes, aromatics or monoterpenes. Five olfactory receptor types were identified according to which compound elicited the strongest neuron response. These potent compounds were (-)-germacrene $D,(-)$ - $\beta$-caryophyllene, methyl salicylate, E- $\beta$-ocimene and (E)-4,8-dimethyl-1,3,7-nonatriene (DMNT). All these compounds are present in the intact strawberry plant and are induced in higher amounts by weevil feeding.

The present study aimed to investigate the significance of two plant volatiles in combination with the aggregation pheromone for enhanced attraction of $A$. rubi. The plant volatiles chosen for this study were (-)-germacrene D and 1,4-dimethoxybenzene. The first compound was tested because previous studies by Innocenzi et al. (2001) and Bichão et al. (2005a) showed that (-)-germacrene D was involved in the insect-plant relationship for $A$. rubi and its host. The second compound 1,4-dimethoxybenzene was chosen as test compound when the results of the present chemical analysis of wild strawberry plants [Fragaria vesca L. (Rosaceae)] were available. This compound was shown to be the dominant compound in the volatile plume of $F$. vesca flowers, in contrast to many $F$. ananassa cultivars where only traces of 1,4-dimethoxybenzene were found (Innocenzi et al., 2001).

\section{Materials and methods}

\subsection{Plant volatiles, collection and identification}

Wild strawberry ( $F$. vesca) plants were brought into the laboratory during May-June, and volatiles of flowers were collected in the laboratory during flowering period (flowering seasons May-June) by SPME (Solid Phase Micro Extraction).

Each flower (still attached on a potted plant) was inserted and enclosed in a glass bulb with two openings used for bulb distillation ( $5 \mathrm{ml}$ volume). In total, five flowers of separate plants were analysed. The openings of the glass cylinder and the bulb were covered by aluminium foil. SPME fibres coated with carbowax/divinylbenzene copolymer, $0.65 \mu \mathrm{m}$ layer were used (Aldrich, Supelco) and exposed $1 \mathrm{~cm}$ from the flower.

\subsection{Chemical analyses}

A Finnigan SSQ 7000 mass spectrometer (EI $70 \mathrm{eV}$, ion source at $150{ }^{\circ} \mathrm{C}$ ) connected to a Varian 3400 gas chromatograph (GC) equipped with a DBwax column (J\&W Scientific ${ }^{\mathrm{TM}}, 30 \mathrm{~m}, 0.25 \mathrm{~mm}$ id and $0.25 \mu \mathrm{m}$ film thickness) was used for analyses of the volatiles. Separation of volatiles was achieved with the temperature program: starting at $40^{\circ} \mathrm{C}(1 \mathrm{~min})$ and increasing at a rate of $4{ }^{\circ} \mathrm{C} /$ min to $220{ }^{\circ} \mathrm{C}$ (12 min). Injections were made with injector temperature of $215^{\circ} \mathrm{C}$ (30 s split less injection).

Volatiles were identified by comparison of their mass spectral data and GC retention times with available reference standards and corresponding mass spectral data available from NIST version 2.0 mass spectral search programme (National Institute of Standards and Technology, USA) and MassFinder 3 mass spectral and retention indexes database (Dr. Hochmuth scientific consulting, Germany). Commercially available references were purchased from Lancaster and Aldrich at highest purity available (>98\%).

\subsection{Traps and lures}

The modified funnel traps used in the experiment were originally developed by AgriSense - BCS Limited for monitoring/controlling the raspberry beetles [Byturus tomentosus De Geer (Coleoptera: Byturidae)] (Fig. 1). The traps consisted of a funnel pointing into a sealed bucket $(2 \mathrm{l})$. Above the funnel, $10 \mathrm{~cm}$ tall Correx white cross vanes were attached to resemble a "giant host plant flower". To protect against different weather conditions a small roof was provided on the top. The traps were baited with strawberry blossom weevil aggregation pheromone sachets and/or host plant volatiles dispensers. The traps were placed in shallow holes in the ground between the strawberry plants leaving the upper third of the bucket and the vanes above the ground. This prevented the traps from falling over. The buckets were filled with $4 \mathrm{dl}$ water. The water served to kill weevils falling through the funnel into the bucket.

The aggregation sex pheromone blend sachets used in the experiments were produced by Agralan Ltd. (The Old Brickyard, Ashton Keynes, Swindon, Wiltshire, SN6 6QR UK). Each sachet dispenser contained $100 \mu \mathrm{l}$ of a blend of Grandlure I, Grandlure II and $( \pm$ )-lavandulol in the 1:4:1 ratio in accordance to the description by Cross et al. (2006a) who showed this mixture was effective in attracting $A$. rubi.

For plant volatile 1 (PV1), germacrene D (100\% (-)-enantiomer, 80\% GC-pure including $\beta$-caryophyllene and $E, E$ - $\alpha$-farnesene distillation fraction of citrus oil from R C Treatt Ltd, Northern Way, Bury St Edmunds, Suffolk, IP32 6NL, UK), polyethylene vials (35 mm

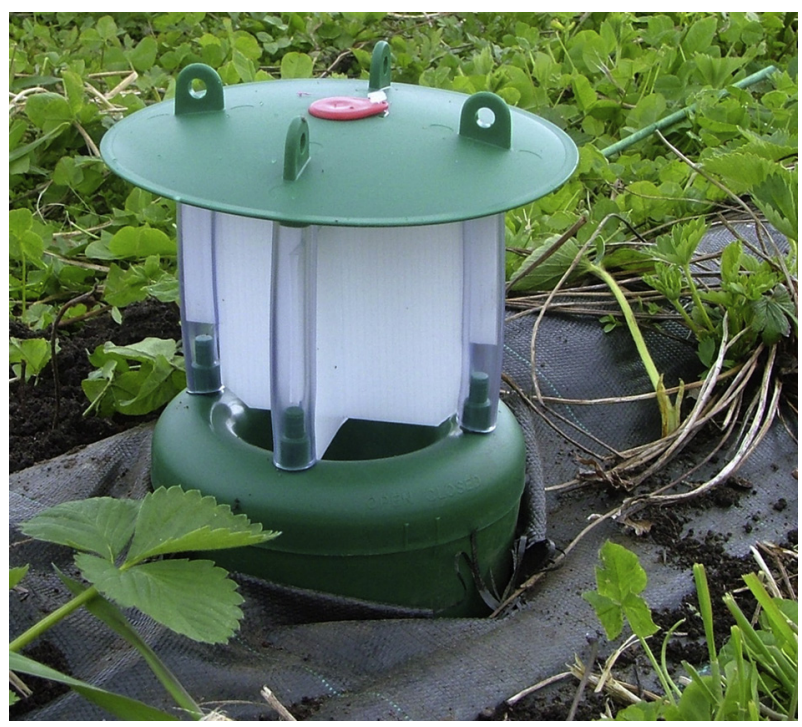

Fig. 1. Insect funnel trap from AgriSense - BCS Limited modified with $10 \mathrm{~cm}$ tall Correx white cross vanes. The traps were baited with strawberry blossom weevil aggregation pheromone sachets and/or host plant volatiles dispensers. 
long, diameter $8 \mathrm{~mm}$, with two side holes diameter $\sim 1 \mathrm{~mm}$ ) were used as lure dispensers. Each vial was initially loaded with $0.50 \mathrm{ml}$ (-)-germacrene D. Polyethylene vials were also used as lure dispensers for plant volatile 2 (PV2), 1,4-dimethoxybenzene (Aldrich $99 \%$ GC-purity). These vials ( $30 \mathrm{~mm}$ long, diameter $12 \mathrm{~mm}$, two side holes diameter $\sim 2 \mathrm{~mm}$ ) were initially loaded with $0.5 \mathrm{~g}$ substance.

\subsection{Field experiments}

At all study sites, 3 replicates of different traps comprising the treatments were distributed in the strawberry fields. There were eight different treatments including one untreated trap as control. Two traps of each series were baited with a single plant volatile, (-)-germacrene D (PV1) or 1,4-dimethoxybenzene (PV2). One trap was baited with the aggregation sex pheromone blend $(\mathrm{Ph})$. The four remaining traps were baited with combinations of these volatiles. The 24 traps at each site were distributed in a completely randomized design. At all sites the traps were distributed with a minimum distance of $5 \mathrm{~m}$ between adjacent traps. The lures were not replaced while the traps were in the fields.

In 2007, the experimental fields were established in week 22-23 (site 12 nd of June and site 24 th of June, see 2.5. Site description) and the traps were inspected approximately once a week until week 33 (16th and 18th of August). In 2008, at site 2 and 3 , the traps were deployed week 18 (1st of May) and inspected until week 33 (13th of August) and week 41 (13th of October), respectively. At site 4, the traps were in the field from week 19 (7th of May) to week 32 (5th of August). The experimental field at site 5 was established in week 15 (9th of April) and the traps were in the field until week 29 (15th of July). In 2008, the traps were inspected approximately every second week.

In 2007, the sampling from the two localities in Norway was initiated a short time before new weevils emerged, thus separation of the overwintering parental generation and the newly emerged weevils was not possible. In 2008, the sampling of weevils was initiated earlier and thus at site 3 and 4 the parental generation (week 20-25) and the new generation (site 3 week 30-33, site 4 week 28-33) could be separated. The second year of samplings was done at four localities; two in Norway, one in Denmark and one in the UK.

\subsection{Site description}

In the selection of study areas, the aim was to use strawberry fields which were grown organically. However, the availability of organic fields (sites 1 and 2) with no use of pesticide was limited thus conventional fields were also included. At these conventional fields, pyrethroids (sites 3 and 4), thiacloprid (sites 3 and 5) or chlorpyrifos (site 5) insecticides were used to target $A$. rubi. Nevertheless, after tests at Bioforsk, Norway, it was shown that resistance has developed in some areas of Norway, and efficacy of using such products is limited (Trandem et al., 2006). In 2007, the experiments were carried out at sites 1 and 2 . The following year the experiments were repeated at sites 2, 3, 4 and 5 .

Site 1. Lundasletta farm, Ørland, South-Trøndelag County, middle part of Norway, coastal area, organic production $\left(63^{\circ} 42^{\prime} 32^{\prime \prime} \mathrm{N}\right.$ $09^{\circ} 43^{\prime} 47^{\prime \prime} \mathrm{E}$ )

Site 2. Sogge farm, Åndalsnes, Møre and Romsdal County, middle part of Norway, in the end of a fjord system/inland area, organic production $\left(62^{\circ} 31^{\prime} 48^{\prime \prime} \mathrm{N} 07^{\circ} 44^{\prime} 04^{\prime \prime} \mathrm{E}\right)$

Site 3. Skjønsby farm, Ringsaker, Hedmark County, southeastern Norway, inland area, conventional production $\left(60^{\circ} 49^{\prime} 58^{\prime \prime} \mathrm{N} 10^{\circ} 47^{\prime} 34^{\prime \prime} \mathrm{E}\right)$.
Site 4. Troldebakkens Frugtplantage, Hørve, Sjælland, Denmark, conventional production, coastal area, $\left(55^{\circ} 45^{\prime} 39^{\prime \prime} \mathrm{N} 11^{\circ} 22^{\prime} 23^{\prime \prime} \mathrm{E}\right)$ Site 5. Middle Pett farm, Bridge, Canterbury, Kent, south-eastern $\mathrm{UK}$, conventional production. Inland area $\left(51^{\circ} 14^{\prime} 20^{\prime \prime} \mathrm{N}\right.$ $01^{\circ} 06^{\prime} 15^{\prime \prime} \mathrm{E}$ )

\subsection{Statistical analysis}

The aim of the experiment was to compare trap efficiency as an effect of treatment. Therefore, proportions of total catch per treatment were calculated by converting the total number of weevil caught in the three traps with the same treatment over the year in each site to proportion of total trapped in that particular site. A comparison of proportion caught (Proc Mixed, SAS Institute. 2009) was done on arcsine square-root transformed proportions, a transformation which fulfilled the assumption of a normal distribution. Estimation technique was restricted maximum likelihood. Degrees of freedom method was Kenward-Roger. Fixed variables were treatment, site and generation. Random variables were trap $\times$ treatment, trap $\times$ treatment $\times$ site.

The model was reduced by removing non-significant higher order interactions (Bibby et al., 2004). Comparisons of individual treatments were done by a mean separation test (Least Square means) (SAS Institute. 2009). The same field at site 2 was used in both 2007 and in 2008. In the analysis across all sites, site 2 is treated as two different sites in each year.

Possible synergistic interaction between treatments PV2 and Ph were tested with a chi-square test. The synergistic effect was defined as a joint effect of these two substances as found in treatment $\mathrm{PV} 2+\mathrm{Ph}$, greater than the additive effect of the individual substances. Two chi-square tests were done -one on the total catches across sites and one for each site.

\section{Results}

\subsection{Chemical analysis}

The volatiles from the five single flowers of $F$. vesca, trapped by SPME during $24 \mathrm{~h}$ and analysed by GC-MS were dominated by 1,4 dimethoxybenzene (mean 96.6\%, SE \pm 1.29). Methyl salicylate (mean $2.2 \%, \mathrm{SE} \pm 0.86$ ) and others minor compounds (mean $1.2 \%$, $\mathrm{SE} \pm 0.80$ ) were also present but these compounds constituted only minor part of the total volatiles.

\subsection{Field experiments}

Altogether, 3515 weevils were caught in the funnel traps across both years and all sites. The three sites with the highest insect caught catch numbers (total $>100$ ) are shown in the left column in Fig. 2 presenting the mean proportion of $A$. rubi in the funnel traps with different treatments at all sites. The results from the sites with lower catch numbers (total < 100) are shown in the right column of Fig. 2. Numbers caught in individual traps on individual trapping dates were too low to allow data to be analysed by a repeated measures analysis, however, a visual analysis of captures allowed us to separate early captures of the overwintering generation from the much larger second generation in sites 3 (2008) and 4 (2008) and to analyse for the effect of generation on proportions captured. As illustrated in Fig. 3 which shows the number of weevils caught in the traps of the three sites with highest captures: at site 1 (2007), site 3 (2008) and site 4 (2008) from middle of May (week 20) to middle of October (week 41), most weevils were captured in periods of approximately one month. At site 1 (2007), in the weeks 26-29, 231 out of 319 weevils were found in the traps. At site 3 (2008), in the weeks 30-33, 1923 out of a total of 2938 weevils 

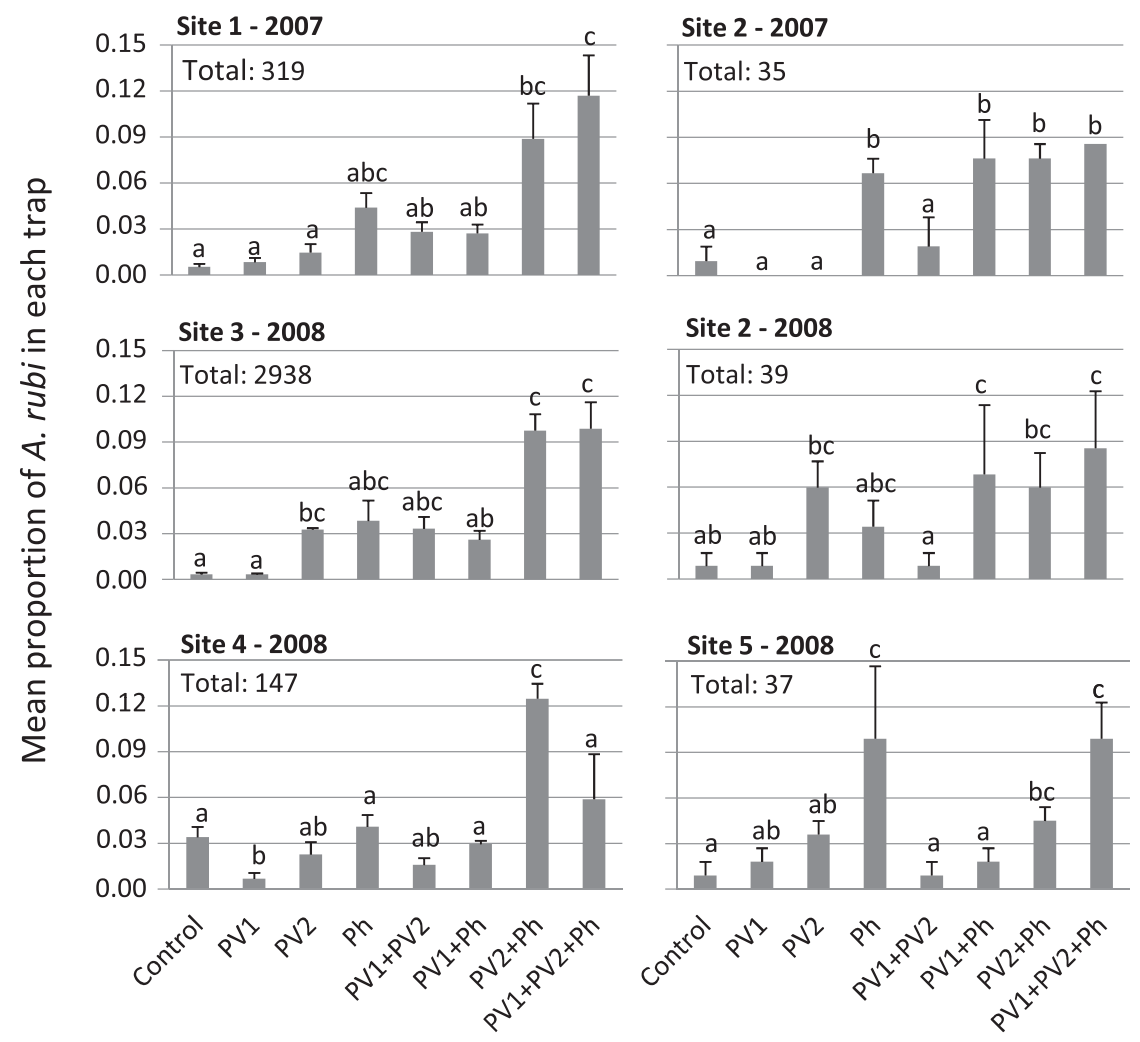

Site 2 - 2008
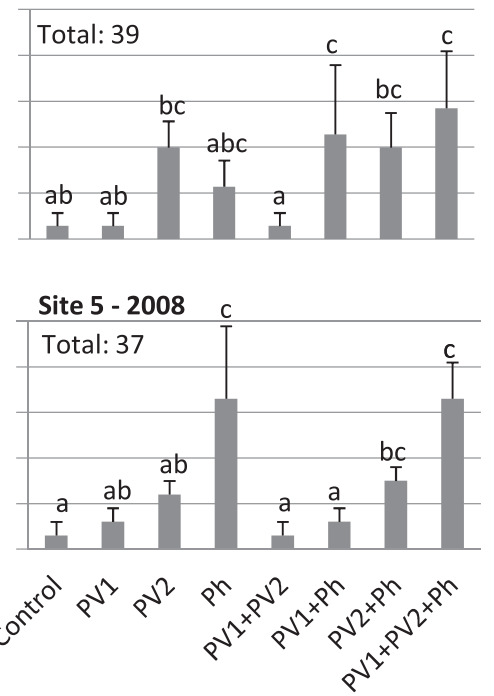

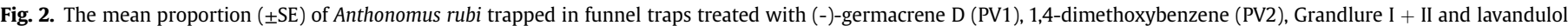

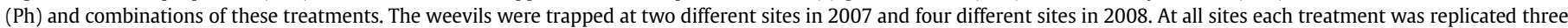

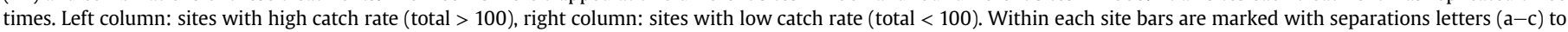
show statistical significance differences $(P<0.05)$ (means separation analysis, SAS Proc Mixed). Total number trapped $A$. rubi is specified for each site.

were found in the traps. At site 4 (2008), 75 out of 147 weevils were trapped in the weeks 28-31. At the other sites (2 (2007), 2 (2008) and 5 (2008)), the numbers of trapped weevils were too low $(<100)$ to observe any such tendencies.

The analysis of proportion $A$. rubi caught showed a significant effect of treatment $\left(F_{7,17.3}=9.66, P<0.0001\right)$, and a significant effect of the interaction of treatment $\times$ site $\left(F_{35}, 83.1=1.65\right.$, $P=0.032$ ). A LS-means comparison ( $t$-test) of proportion weevils captured within sites showed differences between sites of which treatment captured most weevils. However, at all sites with high captures $(>100)$ traps treated with PV2+Ph were among the traps capturing most weevils as in site 4 (2008) where PV2+Ph was significant different from all other treatments. At site 1 (2007) the treatment $\mathrm{PV} 2+\mathrm{Ph}$ was not significant different from $\mathrm{Ph}(t=1.04$, $P=0.3003, \mathrm{df}=165)$ and PV1+PV2+Ph $(t=0.54, P=0.5881$, $\mathrm{df}=165)$, and at site $3(2008) \mathrm{PV} 2+\mathrm{Ph}$ was not significant different from PV2 $(t=-1.50, P=0.1382, \mathrm{df}=74.9), \mathrm{Ph}(t=1.97, P=0.0522$, $\mathrm{df}=74.9)$, PV1+PV2 $(t=-1.72, P=0.0896$, $\mathrm{df}=74.9)$ and $\mathrm{PV} 1+\mathrm{PV} 2+\mathrm{Ph}(t=-0.17, \mathrm{P}=0.8642, \mathrm{df}=74.9)$. Other interaction effects were not significant and were excluded from the final model. The effect of site $\left(F_{35}, 83.1=1.89, P=0.104\right)$ and of generation $\left(F_{1}, 143.3=0.02, P=0.892\right)$ were not significant. The lack of a significant effect of generation show that spring (old) and summer (new) generations of $A$. rubi responded similarly to the treatments.

The means separation test of the highly significant main effect of treatment showed that treatments PV1, PV2 and PV1+PV2 were not significantly different from the control or from each other (Table 1). The treatment PV1+Ph was not different from the $\mathrm{Ph}$ treatment, and $\mathrm{PV} 2+\mathrm{Ph}$ and $\mathrm{PV} 1+\mathrm{PV} 2+\mathrm{Ph}$ were not significantly different from the pure $\mathrm{Ph}$ treatment. However, both $\mathrm{PV} 2+\mathrm{Ph}$ and
$\mathrm{PV} 1+\mathrm{PV} 2+\mathrm{Ph}$ had significantly higher captures than $\mathrm{PV} 1+\mathrm{Ph}$. Captures in PV1+PV2+Ph were not different from those in PV2+Ph. Thus, capture was not improved by adding PV1 to a trap with $\mathrm{PV} 2+\mathrm{Ph}$.

A chi-square test of the numbers of weevils caught in the best performing treatment PV2+Ph compared to the numbers of weevils caught in treatments PV2 and Ph showed synergy between PV2 and $\mathrm{Ph}$ in attracting $A$. rubi across all sites (Chi-square $=43.5, \mathrm{df}=1$, $P<0.0001$ ). The total captures for these three treatments with chisquare values at all sites are shown in Table 2 . It can be noted that synergy between PV2 and Ph was significant for all sites with high captures; site 1 (2007), site 3 (2008) and site 4 (2008).

\section{Discussion}

The results of the chemical analysis of flowers of the wild strawberry $F$. vesca show that one major compound measured by SPME, 1,4-dimethoxybenzene, at a considerable concentration is released. Earlier, only traces of this compound had been found in the headspace of flowers of the strawberry cultivar Korona (Innocenzi et al., 2001, and own unpublished results). Since this compound is dominant in the volatile profile of $F$. vesca flower and in accordance with the results of the present study, this compound may play an important role in host-plant interactions.

The results from the trapping of $A$. rubi showed that traps baited with 1,4-dimethoxybenzene and the aggregation pheromone blend did not catch significantly different numbers of weevils as traps baited with the same treatment plus (-)germacrene D (except for site 4-2008). However, at sites 1-2007 and 3-2008 with the highest catch rates traps baited with these two treatments, the mean 


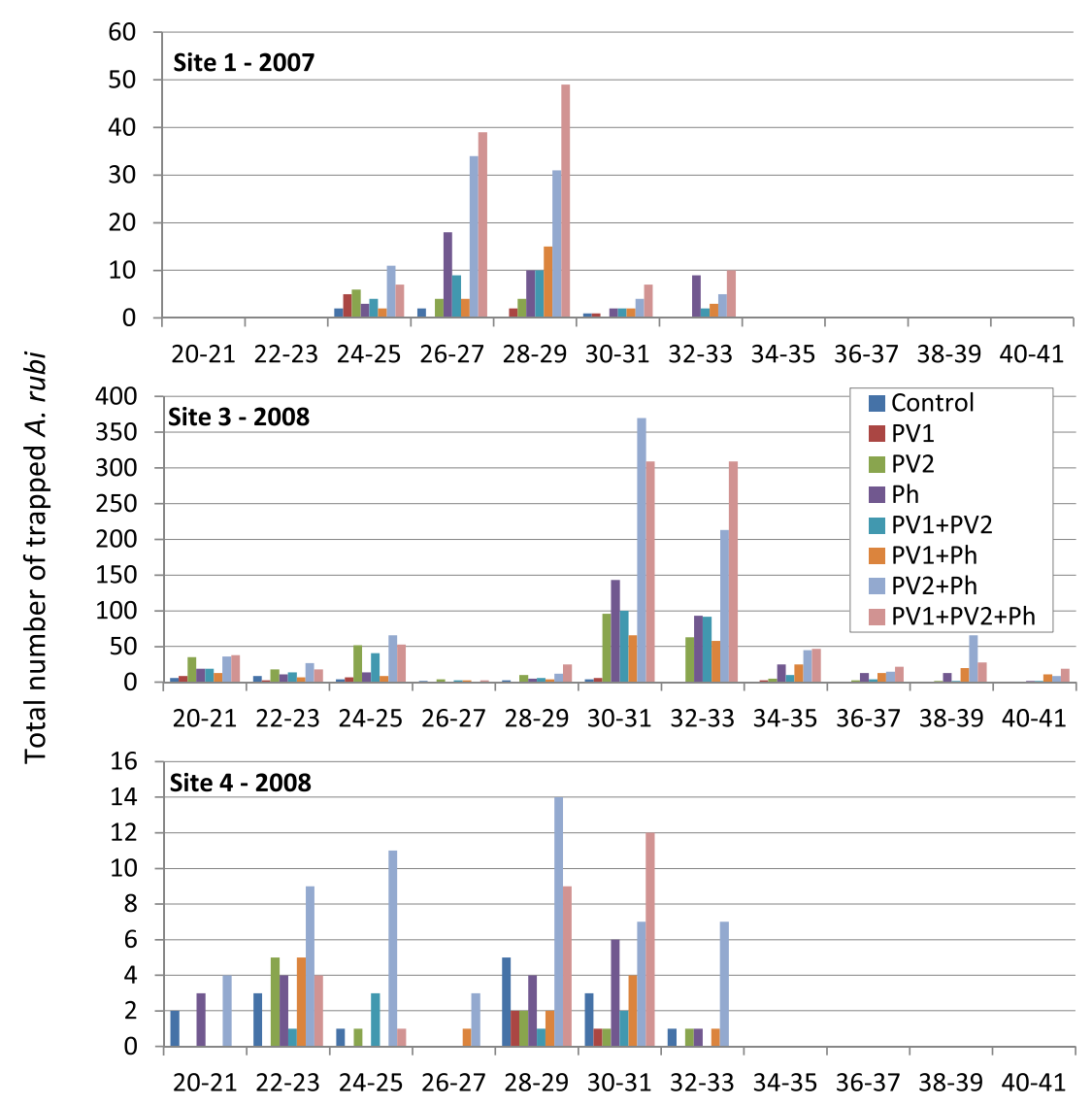

Week numbers

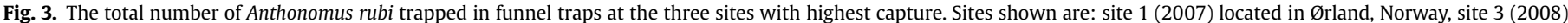

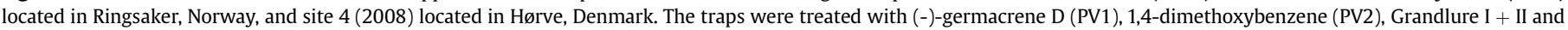
lavandulol $(\mathrm{Ph})$ and combinations of these treatments. Control traps were untreated.

proportions of weevils in each traps were about twice as high or more than traps with other treatment (not statistical significant different at $P<0.05$ for all treatments). This tendency could be the additive effect of 1,4-dimethoxybenzene and the aggregation pheromone blend.

The chi-square test of the number of weevils caught in each trap at all sites showed that there is synergy between the aggregation pheromone blend Grandlure and 1,4-dimethoxybenzene in attracting $A$. rubi. This means that, by using a mixture of these treatments in an insect trap, more weevils are attracted than the sum of individual treatments. This is an important result revealing the significance of plant odours in the chemical communication for A. rubi. The strength of the pheromone signals from one individual to the other is reinforced by relevant plant volatiles. Landolt and Phillips (1997) described how host plant volatiles often synergize or otherwise enhance insect responses to sex pheromones. In this way, insects regulate or mediate sexual communication by utilizing the host plant. The present study demonstrates that $A$. rubi utilizes this mechanism by showing stronger attraction to the aggregation pheromone when it is mixed with a special host plant volatile rather than being exposed to the pheromone alone. This has also been demonstrated for other species. For instance, Dickens (2006) showed that the Colorado potato beetle [Leptinotarsa decemlineata Say (Coleoptera: Chrysomelidae)] had sexually dimorphic responses to plant volatiles with or without pheromones. Males and females of the cranberry weevil [Anthonomus musculus Say (Coleoptera: Curculionidae)] also behave differently when presented to different plant odour blends (Szendrei et al., 2009).
Although we have identified one important host plant volatile for A. rubi, other compounds may also play a crucial role. The other host plant volatile tested in the present study, (-)-germacrene $D$, is a compound released from a wide range of plant species in the family Rosaceae, e.g. apple (Malus domestica Borkh.), (Bengtsson et al., 2001) as well as all analysed cultivars of $F$. ananassa (Innocenzi et al., 2001). It is also released from different species of the Asteraceae family, e.g. Canada Goldenrod (Solidago canadensis L.) (Schmidt et al., 1999) and Mexican sunflower (Tithonia diversifolia Hemsl.) (Moronkola et al., 2007), and species of the genus Bursera (Burser) (Noge and Becerra, 2009). The results from the present study showed that (-)-germacrene D with $E, E$ - $\alpha$-farnesene and $\beta$-caryophyllene as additives to the pheromone blend is of minor importance for attracting the weevils to the traps. However, for many insect species, several host volatile compounds are involved in the search of suitable host plants for feeding, mate location or oviposition (Landolt and Phillips, 1997). Therefore, it is expected that other volatile plant compounds are also important for A. rubi behaviour.

Previous studies have identified 1,4-dimethoxybenzene in the floral odour of other plant species. Andersen (1987) showed that this compound is the major floral volatile component in winter squash [Curcubita maxima Duchesne (Cucurbitaceae)] which can be infested by the polyphagous cucurbit beetle [Diabrotica speciosa Germar. (Coleoptera: Chrysomelidae)], native to South America. In a study by Ventura et al. (2000), it was shown that $D$. speciosa was attracted to yellow sticky traps baited with 1,4-dimethoxybenzene in soybeans crops [Glycine max (L.) Merr. (Fabaceae)]. The authors 
Table 1

The LS-mean proportions $( \pm \mathrm{SE}$ ) of Anthonomus rubi across six different sites trapped in funnel traps treated with two different host plant volatiles (PV1, PV2), aggregation sex pheromone blend $(\mathrm{Ph})$ and combinations of these treatments. Control traps were untreated. Mean values and standard errors followed by the same letter are not significantly different at $5 \%$ level ( $t$-test).

\begin{tabular}{ll}
\hline Treatment & LS-mean proportions \pm SE of $A . r u b i$ \\
\hline Control (untreated) & $0.044 \pm 0.013 \mathrm{a}$ \\
PV1: (-)-germacrene D & $0.038 \pm 0.015 \mathrm{a}$ \\
PV2: 1,4-dimethoxybenzene & $0.094 \pm 0.018 \mathrm{abc}$ \\
Ph: Grandlure I + II and ( \pm )-lavandulol & $0.156 \pm 0.029 \mathrm{~cd}$ \\
PV1: (-)-germacrene D & $0.055 \pm 0.011 \mathrm{ab}$ \\
PV2: 1,4-dimethoxybenzene & \\
PV1: (-)-germacrene D & $0.113 \pm 0.022 \mathrm{bc}$ \\
Ph: Grandlure I + II and ( \pm )-lavandulol & \\
PV2: 1,4-dimethoxybenzene & $0.245 \pm 0.024 \mathrm{~d}$ \\
Ph: Grandlure I + II and ( \pm )-lavandulol & \\
PV1: (-)-germacrene D & $0.255 \pm 0.028 \mathrm{~d}$ \\
PV2: 1,4-dimethoxybenzene & \\
Ph: Grandlure I + II and ( \pm -lavandulol & \\
\hline
\end{tabular}

suggested that traps baited with this compound could be used to reduce beetle populations.

1,4-dimethoxybenzene has also been identified by Döttler et al. (2005) as a floral scent compound of the two Salix species goat willow [S. caprea L. (Salicaceae)] and large gray willow [S. atrocinerea Brot. (Salicaceae)]. They showed that this compound, among others, elicits olfactory responses in the oligolectic bee Andrena vaga Panzer (Hymenoptera: Andrenidae) by using gas chromatographic linked to electroantennogram recordings (GCEAG). In field bioassays, it was also demonstrated that this compound attracts females of $A$. vaga in the beginning of the flight period.

In the studies by Bichão et al. (2005a,b) recording olfactory response of $A$. rubi to host plant volatiles using GC-SCR, no receptor neurons specialized for 1,4-dimethoxybenzene were found. This does not exclude the possibility that $A$. rubi has such olfactory receptor type. Failure to find it could be due to the absence of the compound in the plant volatiles samples used in the study (collected mainly from $F$. ananassa), and/or the limitations of the method that may not reveal all receptor types. Further GC-SCR studies, including $F$. vesca extracts and 1,4-dimethoxybenzene, may reveal specialized receptors for this compound. Since the present study has shown that this compound acts synergistically with the aggregation pheromone blend in attracting weevils, it strongly indicates that $A$. rubi has such a receptor type. Bichão et al. (2005a) described for $A$. rubi a receptor neuron specialized for (-)-germacrene D. Germacrene D has previously been found in increased release rate in the presence of pheromone-producing

Table 2

Total number of Anthonomus rubi in traps treated with A: 1,4-dimethoxybenzene (PV2), B: Grandlure I + II and ( \pm )-lavandulol (Ph) and C: mixtures of these treatments (PV2+Ph), at two sites in 2007 and four sites in 2008. Values of a chi-square test comparing proportion of $\mathrm{A}+\mathrm{B}$ and $\mathrm{C}$ to the sum of captures $(\mathrm{A}+\mathrm{B}+\mathrm{C})$ are also shown.

\begin{tabular}{|c|c|c|c|c|c|c|c|}
\hline \multirow[t]{2}{*}{ Site } & \multicolumn{4}{|c|}{ Treatment } & \multirow[t]{2}{*}{ Chi-square } & \multirow[t]{2}{*}{ df } & \multirow[t]{2}{*}{$P$} \\
\hline & A & B & $\operatorname{Sum} A+B$ & $\mathrm{C}$ & & & \\
\hline $1(2007)$ & 14 & 42 & 56 & 85 & 6.0 & 1 & 0.0146 \\
\hline $2(2007)$ & 0 & 7 & 7 & 8 & 0.1 & 1 & 0.7963 \\
\hline $2(2008)$ & 7 & 4 & 11 & 7 & 0.9 & 1 & 0.3458 \\
\hline $3(2008)$ & 288 & 338 & 626 & 860 & 36.0 & 1 & $<0.0001$ \\
\hline $4(2008)$ & 10 & 18 & 28 & 55 & 8.8 & 1 & 0.0030 \\
\hline $5(2008)$ & 4 & 11 & 15 & 5 & 5.0 & 1 & 0.0253 \\
\hline Total & 323 & 420 & 743 & 1020 & 43.5 & 1 & $<0.0001$ \\
\hline
\end{tabular}

weevils (Innocenzi et al., 2001). In the present study, no significant behaviour modifying effect of this compound was found. One reason could be that the release ratio of (-)-germacrene $\mathrm{D}$ was not adequate. In fact, it has been shown for some species of weevils and mites that the role of the induced compounds is concentration dependent. Some organisms can prefer weakly induced plants to intact plants. However, heavily induced plants are sometimes not preferred (Heil, 2004; Horiuchi et al., 2003). A low concentration of the induced blend might indicate an acceptable plant populated by mates and be attractive, while high concentrations of the induced blend can indicate an overcrowded resource. Thus, the possible impact of (-)-germacrene $\mathrm{D}$ on $A$. rubi behaviour remains to be further investigated.

At site 3-2008 located in south-eastern Norway where most weevils were trapped, in the beginning of the season (until week 25 ) that coincides with the flowering time of $F$. vesca (Sønsteby and Heide, 2008), only A. rubi of the overwintering generation was present (Fig. 3). Therefore, limited number of weevils in the field and in the traps was expected. The increase of weevils in the traps from week 30 is due to the emergence of a new generation. This shift between the generations was also observed at site 4 (2008) located in Denmark, although the period between generations was shorter (from week 25-28) probably due to different climatic conditions. However, these two generations seem to have the same preferences for volatile attraction with no significant differences in response to volatiles between the two generations. This is important knowledge for developing effective traps for controlling weevil damage. The smaller number of $A$. rubi in the traps in the last part of the season may be due to reduced attraction to the pheromone blend. According to strawberry phenological development, no flower buds are available late in the season, thus investments in reproduction will not be profitable.

When a strawberry field is infested by $A$. rubi, it can be expected that the insect population will increase from one year to another if no means are introduced to control the numbers of weevils. A strawberry field is a very unnatural environment with excess of host plants and a limited number of predators for herbivores such as A. rubi. When a population of the strawberry tortricid (Acleris comariana Lienig and Zeller) is established in a strawberry field, it is shown to increase from one year to the next (Sigsgaard et al., 2013). However, at site 2 which is an organic field with no use of pesticides, the numbers of weevils trapped in 2007 and 2008 were both very low and no capture increase was apparent from one year to the other. A population may not also necessarily increase from one year to the next but can be regulated by mortality factors such as weather conditions or natural enemies.

In conclusion, this study shows that funnel traps baited with a combination of the aggregation pheromone blend and the host plant volatile compound 1,4-dimethoxybenzene attracted more A. rubi than the sum of weevils attract to traps baited with the individual treatments. Furthermore, the combination is effective for attracting both generations. This can be a breakthrough in the development of an effective plant protection of strawberry against A. rubi damage without using insecticides. However, a substantial amount of field work needs to be done. To understand the efficiency of such insect trapping system for $A$. rubi, studies addressing mass trapping has to be carried out to. It should be combined with assessment of crop injury and related yield losses to see if it will be economical feasible compared with conventional insecticides. Such aid has been requested by the strawberry producers for a long time, particularly organic growers who do not use pesticides at all. With further study, the system can probably be even further improved by optimizing the plant volatile release rate, adding more attractive compounds and developing more effective traps. 


\section{Acknowledgement}

We would like to acknowledge the owner of the following farms for letting us use their strawberry fields as study sites: Lundasletta farm, Ørland, Norway; Sogge farm, Åndalsnes, Norway; Skjønsby farm, Ringsaker, Norway; Troldebakkens Frugtplantage, Denmark; and Middle Pett farm, UK. We will also acknowledge the Danish Agricultural Advisory Services with advisers Charlotte Hansen and Bodil Damgaard Petersen and the Norwegian Agricultural Advisory Services with adviser Jørn Haslestad for their effort in establishing study sites and sampling field data. Peggy Haugnes and Anne Grete Kleven, research technicians at Bioforsk Organic, gave also important contributions in sampling of field data. This study was funded by The Research Council of Norway through the project Control of weevils in strawberry production by using plant volatiles and other alternative methods (grant number 173279), The Danish Directorate of Food, Fisheries and Agribusiness (grant number 3412-06-01632) and by the Fruit and Vegetable Industry's Trade Association, The Estonian Research Council's Mobilitas top researcher program (project Chemical Ecology grant number MTT2) and Targeted financing from Estonian Ministry of Education and research (grant number SFO180073s08). The ERA-net CORE Organic II project Softpest Multitrap strengthened the collaboration in the preparation of this manuscript.

\section{References}

Agelopoulos, N., Birkett, M.A., Hick, A.J., Hooper, A.M., Pickett, J.A., Pow, E.M. Smart, L.E., Smiley, D.W.M., Wadhams, L.J., Woodcock, C.M., 1999. Exploiting semiochemicals in insect control. Pestic. Sci. 55, 225-235.

Andersen, J.F., 1987. Composition of the floral odor of Cucurbita maxima Duchesne (Cucurbitaceae). J. Agric. Food Chem. 35, 60-62.

Bengtsson, M., Bäckman, A.C., Liblikas, I., Ramirez, M.I., Borg-Karlson, A.K., Ansebo, L., Anderson, P., Löfqvist, J., Witzgall, P., 2001. Plant odor analysis of apple: antennal response of codling moth females to apple volatiles during phenological development. J. Agric. Food Chem. 49, 3736-3741.

Bibby, B.M., Martinussen, T., Skovgaard, I.M., 2004. Experimental Design in Agricultural Sciences. Samfundslitteratur, Copenhagen, 218 p.

Bichão, H., Borg-Karlson, A.-K., Araújo, J., Mustaparta, H., 2005a. Five types of olfactory receptor neurons in the strawberry blossom weevil Anthonomus rubi: selective responses to inducible host-plant volatiles. Chem. Senses 30, 153-170.

Bichão, H., Borg-Karlson, A.-K., Wibe, A., Araújo, J., Mustaparta, H., 2005b. Molecular receptive ranges of olfactory receptor neurons responding selectively to terpenoids, aliphatic green leaf volatiles and aromatic compounds, in the strawberry blossom weevil Anthonomus rubi. Chemoecology 15, 211-226.

Cross, J.V., Easterbrook, M.A., 1998. Integrated Management of Flower Pests of Strawberry. In: Integrated Plant Protection in Orchands "Soft Fruits", vol. 21. IOBC/WPRS Bulletin, pp. 81-87.

Cross, J.V., Hesketh, H., Jay, C.N., Hall, D.R., Innocenzia, P.J., Farman, D.I. Burgess, C.M., 2006a. Exploiting the aggregation pheromone of strawberry blossom weevil Anthonomus rubi Herbst (Coleoptera: Curculionidae): part 1. Development of lure and trap. Crop Prot. 25, 144-154.
Cross, J.V., Hall, D.R., Innocenzi, P.J., Hesketh, H., Jay, C.N., Burgess, C.M., 2006b. Exploiting the aggregation pheromone of strawberry blossom weevil Anthonomus rubi (Coleoptera: Curculionidae): part 2. Pest monitoring and control. Crop Prot. 25, 155-166.

Dickens, J.C., 1989. Green leaf volatiles enhance aggregation pheromone of boll weevil, Anthonomus grandis. Entomol. Exp. Appl. 52, 191-203.

Dickens, J.C., 2006. Plant volatiles moderate response to aggregation pheromone in Colorado potato beetle. J. Appl. Entomol. 130, 26-31.

Döttler, S., Füssel, U., Jürgens, A., Aas, G., 2005. 1,4-Dimethoxybenzene, a floral scent compound in willows that attracts an oligolectic bee. J. Chem. Ecol. 31, 2993-2998.

Heil, M., 2004. Direct defense or ecological costs: responses of herbivorous beetles to volatiles released by wild lima bean (Phaseolus lunatus). J. Chem. Ecol. 30, 1289-1295.

Horiuchi, J.-I., Arimura, G.-I., Ozawa, R., Shimoda, T., Dicke, M., Takabayashi, J., Nishioka, T., 2003. Lima bean leaves exposed to herbivore-induced conspecific plant volatiles attract herbivores in addition to carnivores. Appl. Entomol. Zool. 38, 365-368.

Innocenzi, P.J., Hall, D.R., Cross, J.V., 2001. Components of male aggregation pheromone of strawberry blossom weevil, Anthonomus rubi Herbst. (Coleoptera: Curculionidae). J. Chem. Ecol. 27, 1203-1218.

Landolt, P.J., Phillips, T.W., 1997. Host plant influences on sex pheromone behavior of phytophagous insects. Annu. Rev. Entomol. 42, 371-391.

Moronkola, D.O., Ogunwande, I.A., Walker, T.M., Setzer, W.N., Oyewole, I.O., 2007. Identification of the main volatile compounds in the leaf and flower of Tithonia diversifolia (Hemsl) Gray. J. Nat. Med. 61, 63-66.

Noge, K., Becerra, J.X., 2009. Germacrene D, a common sesquiterpene in the genus Bursera (Burseraceae). Molecules 14, 5289-5297.

Popov, S.Y., 1996. Possibility of monitoring the population density of the strawberry blossom weevil, Anthonomus rubi Herbst (Coleoptera, Curculionidae), on strawberry by two methods: counting clipped buds and using pheromones. Entomol. Rev. 75, 104-109.

Schmidt, C.O., Bouwmeester, H.J., de Kraker, J.-W., König, W.A., 1999. Biosynthese von $(+)$ - und (-)-Germacren D in Solidago canadensis: Isolierung und Charakterisierung zweier enantioselektiver Germacren-D-Synthasen. Angew. Chem. 110, 1479-1481.

Sigsgaard, L., Betzer, C., Naulin, C., Eilenberg, J., Enkegaard, A., Kristensen, K., 2013. The effect of floral resources on parasitoid and host longevity: prospects for conservation biological control in strawberries. J. Insect Sci. 13 (104), 1-17.

Städler, E., 1992. Behavioral responses of insects to plant secondary compounds. In: Rosenthal, G.A., Berenbaum, M.R. (Eds.), Herbivores: Their Interactions with Secondary Plant Metabolites: Ecological and Evolutionary Processes, vol. 2. Academic Press, San Diego, pp. 45-88.

Szendrei, Z., Malo, E., Stelinski, L., Rodriguez-Saona, C., 2009. Response of cranberry weevil (Coleoptera: Curculionidae) to host plant volatiles. Environ. Entomol. 38, $861-869$.

Sønsteby, A., Heide, O.M., 2008. Long-day rather than autonomous control of flowering in the diploid everbearing strawberry Fragaria vesca spp. semperflorens. J. Hortic. Sci. Biotech. 83, 360-366.

Trandem, N., Nordhus, E., Johansen, N., 2006. Pyrethroid resistance found in the strawberry blossom weevil, Anthonomus rubi, in Norway. Nor. Frukt Og. Bær. 9, 32.

Tumlinson, J.H., Hardee, D.D., Gueldner, R.C., Thompson, A.C., Hedin, P.A., Minyard, J.P., 1969. Sex pheromones produced by male boll weevil: isolation, identification, and synthesis. Science 166, 1010-1012.

Ventura, M.U., Martins, M.C., Pasini, A., 2000. Responses of Diabrotica speciosa and Cerotoma arcuata tingomariana (Coleoptera: Chrysomelidae) to volatile attractants. Fla. Entomol. 83, 403-409. 